\title{
The Histopathology of Alimentary Canal of Stinging Catfish Heteropneustes fossilis (Bloch, 1794), Susceptible for Trematodes Incursion
}

Pooja Vishwakarma, Ramakant Maurya', Anand M. Saxena

10.18805/ag.D-5366

\begin{abstract}
Background: Heteropneustes fossilis (Bloch, 1794) is one of the popular freshwater fish known for its food quality and nutritional value. This study was undertaken with an aim to find out histopathological changes in the intestine of freshwater fish Heteropneustes fossilis, host of trematode parasite Masenia vittatusia Agarwal, 1963.

Methods: The intestine of uninfected fish used to determine normal anatomy, while infected intestine to determine pathological changes. The normal histological procedure was followed, which included fixing, rinsing, dehydrating and embedding of tissue. Tissue was cut in 4-6 $\mu \mathrm{m}$ thick sections using a rotary microtome. Haematoxylin and eosin stains were used.

Result: The highest damage was observed in the mucosal layer with ruptured and fused microvilli, hyperplasia of villi, damaged columnar epithelium layer and spread of loose connective tissue into the lumen. Other degenerative modifications included hypertrophy of blood vessels in mucosa and muscularis part, some of them ruptured might be the cause of haemorrhage inside the layers. Other changes include variation in the routine shape of all three layers. The mucosal layer showed aggregation of lymphocytes and mast cells as well.
\end{abstract}

Key words: Heteropneustes fossilis, Hypertrophy, Hyperplasia, lymphocytes, Masenia vittatusia, Trematode.

\section{INTRODUCTION}

Digenetic trematodes, a class of parasitic flatworms that mainly live in the intestine, stomach and gall bladder of fishes. They are important fish infestation agents that may harm their hosts by irritating, damaging and obstructing the tissue. They often induce changes in the layers of the intestine, affecting fish digestion, fish welfare and exposing them to various diseases. As a result, understanding how diseases are spread and the severity of damage is important.

Heteropneustes fossilis (Bloch, 1794) (Cypriniformes: Saccobranchidae) is native to India. It contains a high amount of iron (226 mg100 g-1) and fairly high content of calcium compared to many other freshwater fishes (Saha and Guha, 1939), so it is considered a great source of nutrition. In India, this is high value food fish and a common host for trematode parasite $M$. vittatusia that inhabit the gastrointestinal tract of marine and freshwater bony fishes. Genus Masenia Chatterji, 1933 is often distinguished from the other cephalogonimids by the possession of two rows of enlarged circumoral spines and vitelline follicles located mainly within the hind body (Bray et al., 2008). Present form of Masenia vittatusia Agarwal, 1963, is distinguishable from other species of Masenia in having genital pore slightly away from oral sucker, cirrus- sac overlaps ventral sucker anteriorly, ventral sucker pre-equatorial, sub-spherical, gonads sub-equal, vitellarium confined in the lateral field and uterus post-testicular (Fig 1).

The histopathological studies not only provide an errorfree diagnosis of diseases but also gives information about
Department of Zoology, Helminthology Laboratory, University of Lucknow, Lucknow-226 007, Uttar Pradesh, India.

${ }^{1}$ Department of Zoology, Maharishi University of Information Technology, Lucknow-226 013, Uttar Pradesh, India.

Corresponding Author: Pooja Vishwakarma, Department of Zoology, Helminthology Laboratory, University of Lucknow, Lucknow-226 007, Uttar Pradesh, India.

Email: poojavishwakarma19900@gmail.com

How to cite this article: Vishwakarma, P., Maurya, R. and Saxena, A.M. (2021). The Histopathology of Alimentary Canal of Stinging Catfish Heteropneustes fossilis (Bloch, 1794), Susceptible for Trematodes Incursion. Agricultural Science Digest. DOI: 10.18805/ ag.D-5366.

Submitted: 01-05-2021 Accepted: 15-06-2021 Online: 30-07-2021

pathogenicity of these parasites as well. All the layers of the intestine contribute to the distinct properties such as the mucus layer covers the lumen of the digestive tract and maximizes its function (Dezfili et al., 2009; Sanil et al., 2010; Matos et al., 2017). The increase in fluke infection may be the cause of intestinal secretion, changes in the mucosa and submucosa. Though many studies have been conducted on fish trematodes, relatively few studies have focused on histopathological changes in host tissues (Bose and Sinha, 1979; Barbara, 1980; Chung Yui-tan 1981; Gupta and Agarwal, 1983). Therefore, the present study deals with the histopathological effects on fish intestine derived due to infestation of trematode parasite $M$. vittatusia Agarwal, 1963. 


\section{MATERIALS AND METHODS Collection of fish}

Heteropneustes fossilis (Bloch, 1794) is a fish found throughout the year. Collection part of research work was completed in the Helminthology Laboratory, Department of Zoology, University of Lucknow, Lucknow. A two- year survey, from January 2018 to December 2019, was performed to see the parasitic load in the gastrointestinal tract of fish. A total number of 248 fish were collected from the Gomti River, Lucknow, identified with the help of the handbook "Fishes of U. P. and Bihar" (Srivastava, 2002) and dissected. The entire alimentary canal is removed, kept in physiological saline $(0.9 \%)$, washed multiple times to remove tissue and fats debris and thoroughly examined to check the presence of trematode parasites. Specimen of trematode parasites fixed in A.F.A fixative and preserved in $70 \%$ alcohol for taxonomy purpose. Parasites were identified using Systema Helminthum' by Satyu Yamaguti, Part I, Digenetic trematode of fishes, (1953).

\section{Histopathological analysis}

Histopathology part of research work conducted in Central laboratory (DST-FIST), Department of Zoology, University of Lucknow, Lucknow in September - October 2019.

To perform the histopathological analysis, infected and uninfected fragments of intestine were fixed in Bouin's fixative (picric acid fixative) for 12-24 hours, washed and preserved in $70 \%$ alcohol. All the histological procedures performed using the histological protocol in accordance with Suvarna et al. (2018). For staining purposes, haematoxylin and eosin stains were used and sections were photographed using a Nikon compound microscope (Eclipse E200, Japan).

\section{RESULTS AND DISCUSSION}

The intestine in $H$. fossilis starts from the end of the pyloric region of the stomach, anterior intestine, posterior intestine and end with the rectum (Fig 2). Earlier, Rashad et al., (2004) also described the four regions of the intestine in teleosts. We recovered maximum parasites from the anterior part of the intestine, hence we used this part for histological analysis purpose.

\section{General morphology of alimentary canal}

The anterior part of the intestine consisted of three layers, the mucosal layer is innermost layer of the digestive tract; its luminal face is directly in contact with ingested food and is highly specialised for the digestion, absorption, secretion and immune processes that occur along the digestive tube (Ross and Pawlina, 2016). The layer contains numerous folds of finger-like projections called microvilli that increase surface area for proper absorption of food (Fig 3A). The mucosa layer consists of two layers, one is lamina epithelium that contributes to absorptive and secretory function and another one is lamina propria, which consists of lose connective tissues. The columnar epithelium of mucosa rich in specialized goblet cells (Fig 3D) that may secrete mucus throughout the gastrointestinal tract. The presence of lacteal was also observed within villi where capillaries absorb the nutrients from villi. The second layer of the intestine is muscularis that comprises an inner circular layer and another outer longitudinal layer of smooth muscle cells. The outermost layer is the serosa where terminal alimentary canal may open into the anus.

\section{Pathological manifestations}

In $H$. fossilis maximum changes were observed in the mucosal layer; the columnar epithelium is broken at several places, high burden of parasites conjointly affected the lamina propria that significantly peeled off into the lumen (Fig 4A). Shahin et al. (2013) observed shortening of intestinal villi or compressions of mucosal folds in Clarias batrachus. On the other hand, we observed hyperplasia of villi along with fused microvilli (Fig 4A and B). Reddy et.al. (2013), had seen fibrosis, hyperplasia and metaplasia in the intestine of Channa striatus which might be associated

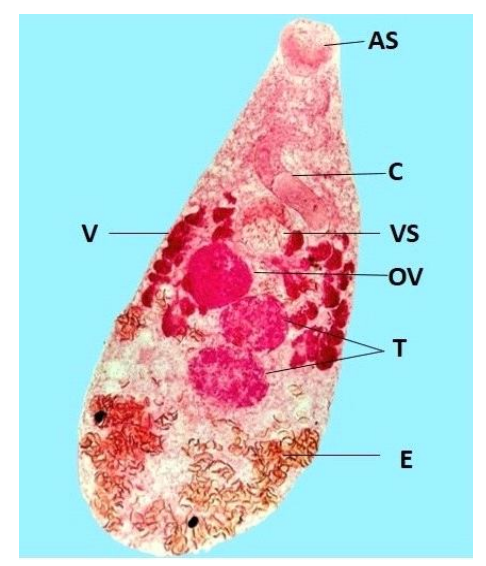

Fig 1: M. vittatusia Agarwal, 1963, a trematode parasite of Gastrointestinal Tract of Heteropneustes fossilis (Bloch, 1794).

Abbreviations: AS- anterior sucker or oral sucker, VS- ventral sucker, C-cirrus sac encloses bipartite seminal vesicle, OV- ovary, T- testes, V- Vitellaria and E- eggs. Aceto-alum carmine stain, 10X.

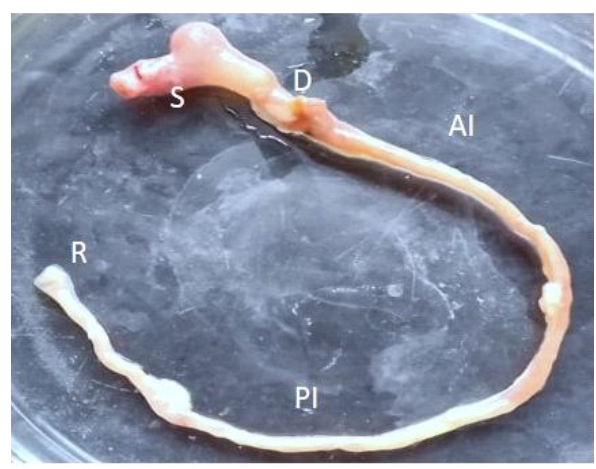

Fig 2: the alimentary canal of Heteropneustes fossilis (Bloch, 1794) consists of stomach (S), duodenum (D), anterior intestine $(\mathrm{Al})$, posterior intestine and rectum $(\mathrm{R})$. 

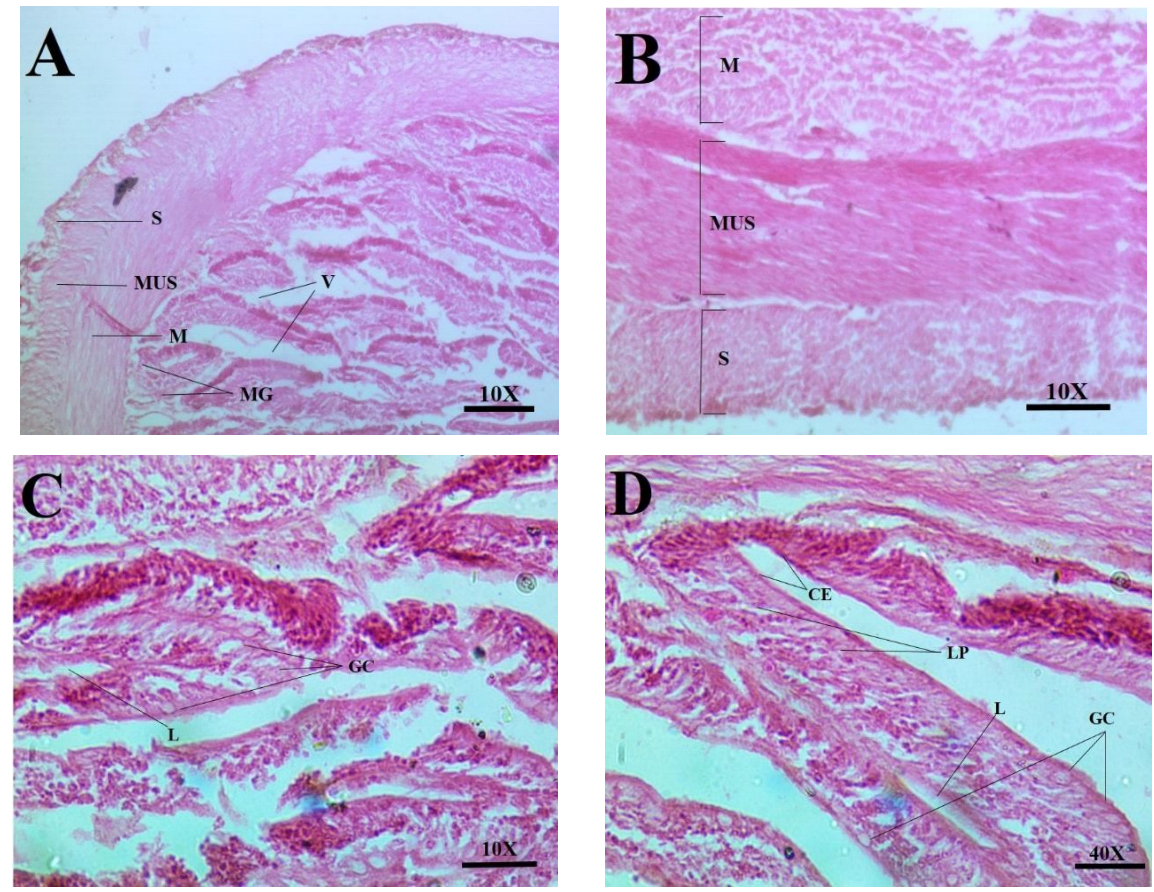

Fig 3: T.S of intestine of uninfected Heteropneustes fossilis (Bloch, 1794), photographs showing (A) layers of the intestine showing serosa, muscularis and mucosa with villi and microvilli, (B) all three layers, (CandD) T.S of mucosal layer showing microvilli contains epithelium (CE), goblet cells (GC) and blood vessels, lacteal (L) is present within villus. Abbreviations: S-Serosa, MUS- Muscularis, M-Mucosa, MG-mucosal gland, V-villi, CE-columnar epithelium, L-Lacteal, GC- Goblet cells, LP- Lamina propria. H.E staining, 10X, 40X.
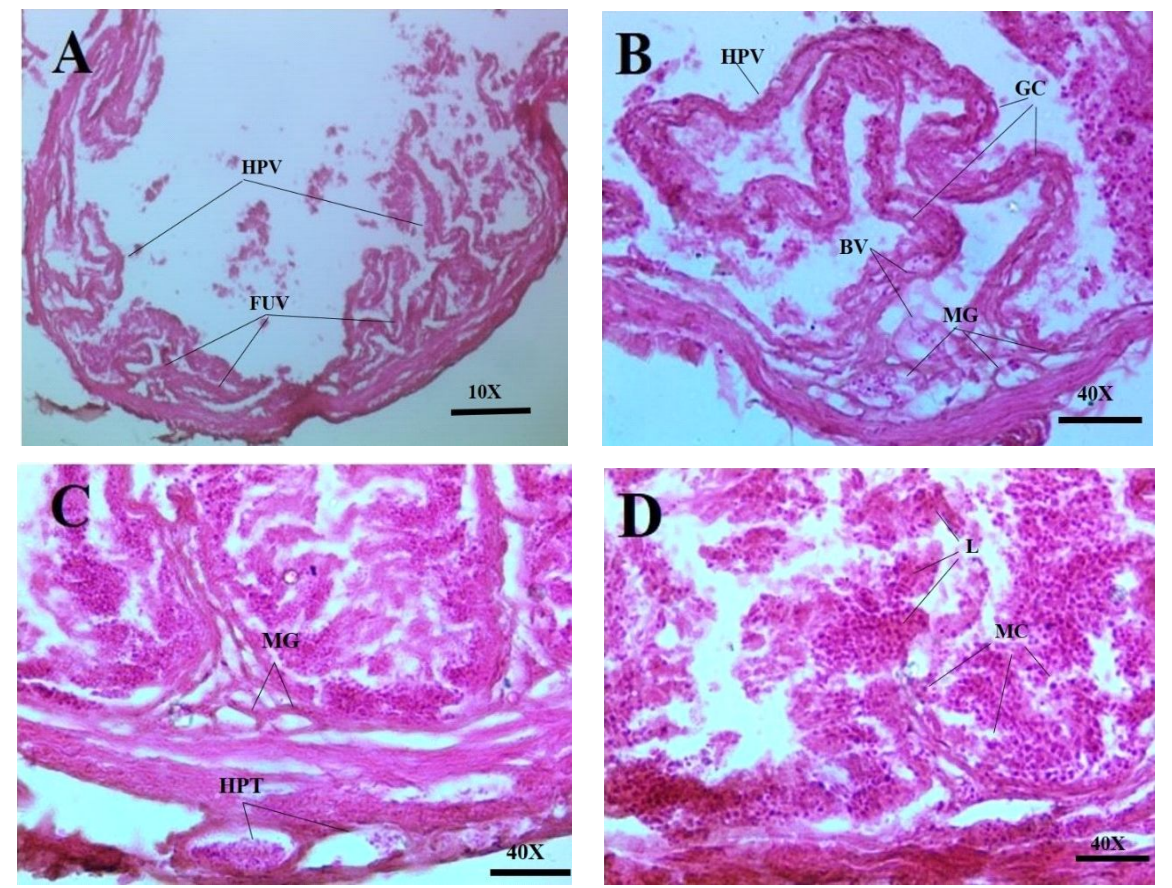

Fig 4: T.S of infected alimentary canal of Heteropneustes fossilis (Bloch, 1794). (AandB) alteration in mucosal layer is seen. (A) Villi fused together, some of them got ruptured and scattered in the lumen, (B) enlarge view of villi showing hyperplasia of villi (HPV), changed routine shape of blood vessels, mucosal glands and goblet cell (BV; MG; GC), goblet cells increased, (C) Hypertrophy of blood vessels (HPT) in mucosa and muscularis layers (D) aggregations of mast cells (MC), lymphocytes (L). Abbreviations: HPVhyperplasia of villi, FUV-fused villi, GC-goblet cell, MG-mucosal gland, BV-blood vessel, HPT- hypertrophy of blood vessel, Llymphocyte, MC-mast cell. H.E stain. 10X, 40X. 
with changes in organ morphology, physiology, metabolism and secretory efficacy as well. We found increased goblet cells number in epithelium that are somewhat similar to $\mathrm{K}$ Cinar et.al. (2006) (Fig 4B) but here goblet cells were found flattened than routine shape. Other mucosal glands were observed with changes in their regular shape. In the mucosa and muscularis layer, we noticed hypertrophy in blood vessels that might cause haemorrhage inside the layers ( $\mathrm{Fig} B$ and $\mathrm{C}$ ). Our findings also reveal the prevalence of mast cell and lymphocytes within the mucosa (Fig 4D).

M. vittatusia Agarwal, 1963 is a predominant trematode parasite of the $\mathrm{Gl}$ tract of freshwater fish $H$. fossilis. Two suckers of this endo-parasite may adapt to maintain attachment with internal organs of the host such as the intestine and blood vessel where it not only gets nutrition to survive but also completes its definitive phase of life cycle. Collectively, this pathogen caused severe inflammation to fish tissue which can be identified by hyperplasia in villi, hypertrophy or swelling in blood vessels. Aggregation of mast cells and lymphocytes is evidence showing an immune response against the pathogenic agent. However, inflammation is a protective mechanism posed by the host $H$. fossilis but parasite may have caused considerable harm to its host tissue, as a result, damaged connective tissue shaded into the lumen and epithelial cell number increased. The current histopathological status of the tissue suggests that the worm possibly disrupted the host's routine physiological process and impaired the metabolism.

\section{CONCLUSSION}

Heteropneustes fossilis (Bloch, 1794) is a very nutritious and economically important food fish in India, serves as a host for digenean flatworm belongs to the family Maseniidae Yamaguti, 1954. M. vittatusia adheres to the intestine and blood vessels of the host by an oral and ventral sucker and cause extensive damage to these parts. Such damages not only affect the intestine but also impair food absorption that may be associated with the malnutrition of fish. The reduced surface area in the lumen, hyperplasia in villi, damage of blood vessels and change in routine shape of glands can affect the whole digestion of nutrients and spoil the food quality as well. Increased parasitism may be responsible for increased mortality and reduced commercialization of fishes. Histopathology of the internal organ of fish gives an insight into the lesions and also an opportunity to seek out parasites borne diseases which provide a concept to prevent them.

\section{ACKNOWLEDGEMENT}

We are grateful to the University Grants Commission (U.G.C.), New Delhi, India (CSIR-UGC, NET/ JRF), Government of India, for financial support. We would also like to thank Department of Zoology, University of Lucknow, for providing all necessary laboratory facility during research.

\section{REFERENCES}

Agarwal, V. (1963). On three trematodes from the intestine of a fresh water fish Mystus vittatus (BI.) from Lucknow. Indian J. Helminth.15: 138-147.

Bray, R.A., Gibson, D., Jones. (2008). A keys to the Trematoda Volume 3. CAB International and Natural History Museum, London.

Bose, K.C. and Sinha, A.K. (1979). The histopathology of the stomach of the fish Channa gachua (Ham) (Channidae). Attributable to the digenetic trematode, Genarchopsis goppo (OZAKI), Hemiuuridae. Current Science. 48(16): 747-748.

Barbara, B. (1980). Pathological changes in cyprinid fry infected by Bucephalus polymorphus and Rhipidocotyle illensis metacercariae (Trematoda: Bucephalidae). Act. Parasitol. Pol. 27(15-18): 241-246.

Chatterji, R.C. (1933). On the trematode parasites of a Rangoon siluroid fish Clarias batrachus (Linneus, 1785). Bull. Acad. Sci. Allahabad. 3: 33-40.

Cinar, K. and Senol, N. (2006). Histological and histochemical characterization of the mucosa of the digestive tract in flower fish (Pseudophoxinus antalyae). Anat Histol Embryol. 35: 147-151.

Chung, Yui-tan. (1981). A study on the histopathology in the Wolfian ducts of Hypentelium nigricans (Osteichthyes: Catostomidae) caused by Phyllodistomum superbum (Trematoda: Gorgoderidae). Q.J. Taiwanmus (Taipeli). 34(3/4): 237240.

Dezfuli, B.S., Szekeli, C., Giovinazzo, G., Hills, K. and Giari, L. (2009). Inflammatory response to parasitic helminths in the digestive tract of Anguilla anguilla (L.). Aquaculture. 296: $1-6$.

Gupta, A.K. and Agarwal, S.M. (1984). Host-parasite relations in Channa punctatus and Euclinostomum heterostomum. Transaminase and total proteins and free aminoacids. Current Science. 53: 710-711.

Rashad, M. and Fath El-Bab. (2004). Fundamentals of the Histology of Fish, Part I Histology of Teleosts. Second edition.

Suvarna Kim S., Layton Christopher and Bancroft John D. (2018). Bancroft's Theory and Practice of Histological Techniques. Elsevier, $8^{\text {th }}$ Edition.

Matos, L.V., Oliveira, M.I.B., Gomes, A.L.S. and Silva, G.S. (2017). Morphological and histochemical changes associated with massive infection by Neoechinorhynchus buttnerae (Acanthocephala: Neoechinorhynchidae) in the farmed freshwater fish Colossoma macropomum Cuvier, 1818 from the Amazon State, Brazil. Parasitology Research. 116(3): 1029-1037.

Reddy, B.L. and Benarjee G. (2013). Intestinal histopathology of trematode infected fish, Channa straitus. Biolife: An International Journal of Biology and Life Sciences. 1(1): 29-31.

Ross, M.H. and Pawlina, W. (2016). Histology: A text and atlas with correlated cell and molecular biology. Philadelphia: Lippincott Williams and Wilkins. ISBN 978-85-277-2964-2. $7^{\text {th }}$ Edition.

Saha, K.C. and Guha, B.C. (1939). Nutritional investigation on Bengal fish. Indian Journal of Medical Research. 26: 921- 927. 
The Histopathology of Alimentary Canal of Stinging Catfish Heteropneustes fossilis (Bloch, 1794), Susceptible for...

Srivastava, G.J. (2002). Fishes of Uttar Pradesh and Bihar Vishwavidyalaya Prakashan, Varanasi, India, pp. 1-203. $9^{\text {th }}$ Ed.

Sanil, N.K., Asokan, P.K., John, L. and Vijayan, K.K. (2010). Pathological manifestations of the acanthocephalan parasite, Tenuiproboscis sp. in the mangrove red snapper (Lutjanus argentimaculatus, Forsskål, 1775), a candidate species for aquaculture from Southern India. Aquaculture. 310(3-4): 259-266.
Shahin, M.I.H., Chandra, K.J. Das, D.R. and Khalil, S.M.I. (2013) Morphology and histopathology of alimentary canal of Clarias batrachus (Linnaeus) and Heteropneustes fossilis (Bloch). International Research Journal of Applied Life Sciences. 2(03): 11-20.

Yamaguti, S. (1954). Helminthum. Vol 1. The Digenetic Trematodes of fishes. Published by author. Tokyo (1953). 